\title{
APLIKASI PENCARIAN TEMPAT WISATA BERBASISKAN GPS DENGAN METODE RADIUS DAN RATING
}

\author{
Budi Yulianto ${ }^{1}$; Rita Layona ${ }^{2}$ \\ ${ }^{1,2}$ Computer Science Department, School of Computer Science, BINUS University \\ Jln. K.H. Syahdan No. 9, Palmerah, Jakarta Barat, 11480 \\ ${ }^{1}$ laboratory@binus.ac.id; ${ }^{2}$ rlayona@binus.edu
}

\begin{abstract}
Tourist place navigation application becomes more important for travelers, especially backpackers. Previous research had produced applications which can only show the route from the position of traveler to tourist place with map shown. The goal of the research is to use the radius and rating method that is still rare in the community to navigate tourist place. Output of the research is a GPS-based application that can display the search results of tourist sites based on rating and radius method, route from the traveler to the destination place, and description of the place. Development method used waterfall that contained user requirement, analysis, design, coding and testing, implementation, and maintenance. Conclusion of the research has shown that the developed application provided convenience in searching tourist places based on radius and rating, displaying route, and description of tourist places.
\end{abstract}

Keywords: backpacker, tourism, GPS, radius, rating

\begin{abstract}
ABSTRAK
Aplikasi pencarian lokasi tempat wisata menjadi penting bagi wisatawan, khususnya backpacker. Penelitian sebelumnya telah menghasilkan aplikasi yang hanya dapat menampilkan rute dari posisi wisatawan ke lokasi wisata dengan penambahan grafis peta. Penelitian ini bertujuan untuk menggunakan metode radius dan rating yang masih jarang di masyarakat dalam pencarian lokasi wisata. Hasil dari penelitian ini berupa aplikasi berbasiskan GPS yang dapat menampilkan hasil pencarian lokasi wisata berdasarkan metode radius dan rating, rute dari lokasi wisatawan ke lokasi yang dituju, dan deskripsi lokasi. Metode perancangan menggunakan waterfall yang meliputi tahapan user requirement, analisis, desain, pengkodean dan pengujian, implementasi, dan perbaikan. Simpulan yang didapat dari penelitian ini yaitu aplikasi memberi kemudahan dalam mencari lokasi wisata berdasarkan radius wisatawan dan rating, memberikan rute, dan deskripsi tempat wisata.
\end{abstract}

Kata kunci: backpacker, wisata, wisatawan, GPS, rute 


\section{PENDAHULUAN}

Pariwisata merupakan kegiatan wisata dinamis yang melibatkan banyak manusia serta menghidupkan berbagai bidang usaha (Ismayanti, 2011). Dalam kepariwisataan, terdapat 3 elemen utama, yaitu wisatawan, geografi, dan industri. Wisatawan merupakan orang yang melakukan aktivitas wisata. Geografi adalah pergerakan wisatawan dari daerah asal daerah transit, dan daerah tujuan. Industri adalah penyedia jasa wisata.

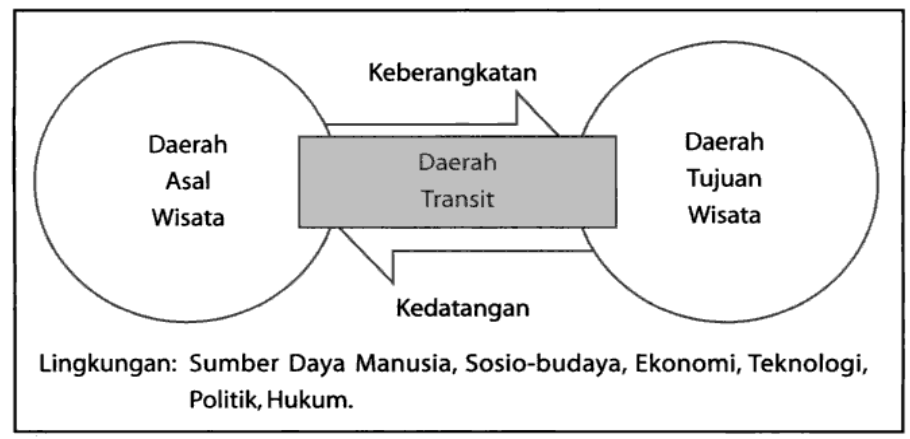

Gambar 1 Elemen Geografi Pariwisata

Pariwisata merupakan salah satu sumber devisa bagi Negara Indonesia. Berdasarkan data Kementerian Pariwisata dan Ekonomi Kreatif Republik Indonesia pada bagian Ranking Devisa Pariwisata, devisa yang dihasilkan dari pariwisata bernilai 4,447.97 juta USD di peringkat ke-6 pada 2006 dan pada 2010 devisa pariwisata meningkat menjadi 7,603.45 juta USD di peringkat ke-4 (Kementerian Pariwisata dan Ekonomi Kreatif Indonesia, 2012). Berdasarkan data tersebut, dukungan terhadap peningkatan sektor pariwisata diperlukan untuk meningkatkan devisa bagi Negara Indonesia. Salah satu cara adalah dengan memberikan kemudahan kepada para wisatawan berupa aplikasi yang dapat menyediakan informasi lokasi wisata dan jalur menuju lokasi tersebut (Khraisat, Al-Khateeb, Abu-Alreesh, et al, 2011).

Sebagian wisatawan tidak menggunakan jasa biro maupun agen perjalanan. Para wisatawan tersebut kerap disebut dengan istilah backpacker. Para backpacker pada umumnya memilih untuk tidak menggunakan jasa biro maupun agen karena alasan (penghematan) finansial, kebebasan (tidak perlu terjadwal), dan privasi (Ismayanti, 2011). Para backpacker tentunya mengandalkan kemampuan sendiri untuk berwisata dan juga memerlukan alat bantu untuk mendapatkan informasi lokasi wisata dan jalur menuju lokasi tersebut (Hallo, Beeco, Goetcheus, et al., 2012).

Penelitian sebelumnya telah menghasilkan aplikasi yang hanya dapat menampilkan peta wisata pada perangkat mobile (Lai, Li, Chan, et al, 2007), titik koordinat pengguna (Simon \& Williams, 2008), pencarian tempat secara regional (Feng, Rizos, Higgins, et al, 2009), rute dari posisi wisatawan ke lokasi tersebut (Yulianto, 2010), dengan penambahan grafis peta (Chu, Lin, Chang, et al, 2011), dan grafis lokasi 2 dimensi (Ruotsalainen, Kuusniemi, \& Chen, 2011). Penelitian terbaru telah menambahkan informasi angkutan umum yang dapat digunakan untuk menuju tempat wisata (Edwards \& Griffin, 2013) dan informasi angkutan umum yang sedang melintas menuju wisatawan (Shimizu, Yamaguchi, Ai, et al, 2014). Masih jarang penelitian yang menghasilkan aplikasi yang dapat menampilkan tempat wisata dengan metode radius dan rating.

Penelitian ini bertujuan untuk menghasilkan sebuah aplikasi wisata pada Indonesia untuk mempermudah para wisatawan, khususnya backpacker, tanpa menggunakan (atau dapat sebagai 
pelengkap) jasa agen atau biro perjalanan wisata. Aplikasi akan memberikan data tempat wisata yang dapat dikunjungi dalam radius tertentu dari lokasi pengguna beserta jalur untuk menuju ke tempat wisata tersebut (Steiniger, Neun, \& Edwardes, 2006). Aplikasi juga akan menampilkan daftar tempat wisata berdasarkan peringkat agar menjadi masukan bagi wisatawan dalam memutuskan suatu lokasi wisata yang ingin dikunjungi.

\section{METODE}

Penelitian ini menerapkan metode waterfall dalam perancangan aplikasi yang meliputi tahapan sistem perancangan, analisis, desain, pengkodean dan pengujian, implementasi, dan perbaikan (Sommerville, 2011). Karakteristik waterfall berupa aktivitas yang mengalir dari satu fase (tahapan) ke fase lainnya secara berurutan, dan setiap fase dilalui terlebih dahulu hingga selesai untuk menuju fase berikutnya. Gambar 2 menunjukkan diagram alir metode perancangan dalam penelitian.

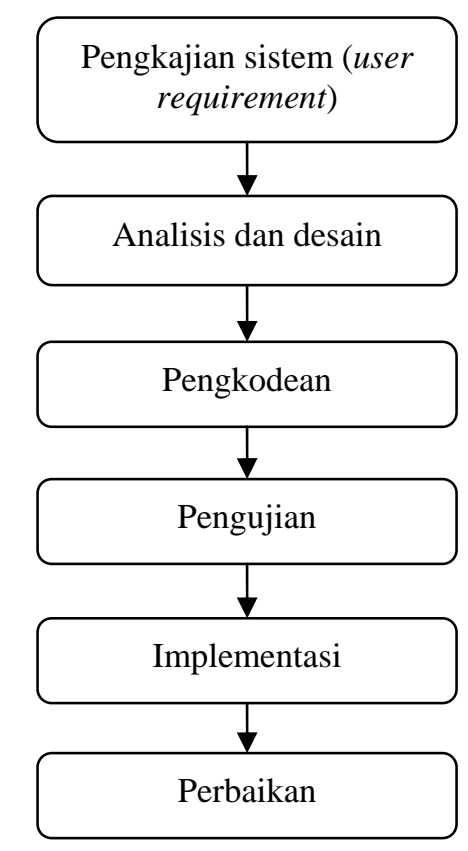

Gambar 2 Diagram Alir Metode Perancangan

Pada tahapan user requirement, penelitian melakukan proses pengumpulan data lokasi wisata dan kebutuhan fitur dari sistem yang akan dibuat melalui kuesioner kebutuhan pengguna. Pada tahapan analisis dan desain, penelitian mengolah hasil data lokasi wisata dan kuesioner kebutuhan pengguna, dan menerjemahkan ke dalam bentuk rancangan sistem dan tatap muka (tampilan) peranti lunak.

Selanjutnya memasuki tahap pengkodean dan pengujian (code and testing), hasil dari tahapan desain diimplementasikan menggunakan bahasa pemrograman yang dimengerti oleh komputer untuk menghasilkan peranti lunak yang dapat bekerja. Tahap ini merupakan implementasi dari tahapan desain yang secara teknis akan dilakukan oleh programmer. Tahapan pengkodean akan dilakukan secara bersamaan dengan uji coba untuk menguji kekurangan program maupun fungsi dari sistem. 
Setelah semua fungsi peranti lunak diuji untuk meminimalkan kesalahan (error) dan memaksimalkan kesesuaian dengan kebutuhan yang sudah didefinisikan sebelumnya, maka tahapan selanjutnya adalah implementasi sistem baru untuk dijalankan. Tahapan terakhir adalah pemeliharaan sistem, termasuk di dalamnya adalah pengembangan. Ketika sistem dijalankan, terdapat kemungkinan terjadinya kesalahan minor yang tidak ditemukan sebelumnya, ataupun adanya penambahan fungsi baru. Pengembangan diperlukan ketika adanya perubahan yang terjadi seperti pergantian sistem operasi.

\section{HASIL DAN PEMBAHASAN}

Analisis terhadap data diperlukan untuk mendukung penelitian melalui kuesioner. Hasil kuesioner diolah untuk mendapatkan informasi kebutuhan dari sisi pengguna dalam menunjang pengembangan fitur aplikasi yang diperlukan (Whitten \& Bentley, 2007). Kuesioner berisi 5 pertanyaan utama yang diberikan kepada 104 responden dengan hasil berikut.

Pada pertanyaan tentang frekuensi berwisata (Gambar 3), sebanyak 43\% responden melakukan perjalanan wisata setidaknya 1-2 kali dalam 1 tahun.

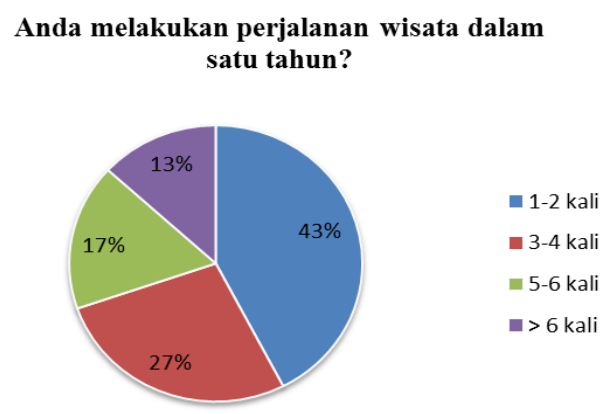

Gambar 3 Frekuensi Berwisata

Kemudian, pada pertanyaan tentang frekuensi penggunaan GPS sebagai navigator dalam perjalanan wisata (Gambar 4), 28\% responden selalu menggunakan aplikasi navigasi saat berwisata, dan 38\% sering menggunakan. Data ini menunjukkan bahwa 2 dari 3 wisatawan menggunakan aplikasi navigasi untuk berwisata.

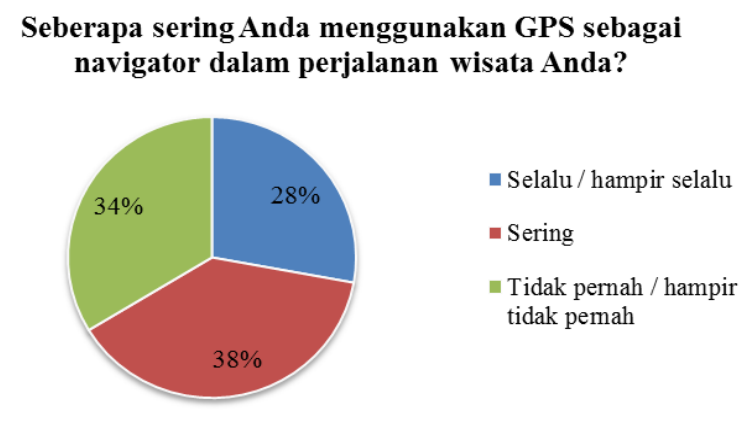

Gambar 4 Frekuensi Penggunaan Aplikasi 
Lalu pada pertanyaan tentang alasan responden menggunakan GPS (Gambar 5), mayoritas pengguna (74\%) menggunakan aplikasi karena tidak mengetahui jalan menuju lokasi wisata.

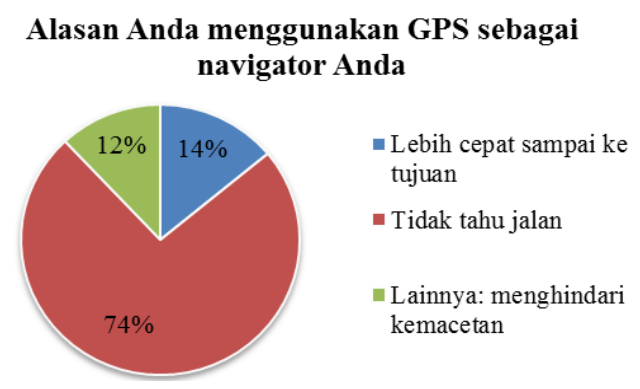

Gambar 5 Alasan Menggunakan Aplikasi

Selanjutnya pada pertanyaan tentang fitur aplikasi, "Deskripsi Tempat” diperlukan responden (75\%), "Rating" (63\%), "Review" (50\%), dan "Foto" lokasi wisata sebesar 55\%. Data ini akan menjadi rujukan dalam pengembangan fitur aplikasi ini.

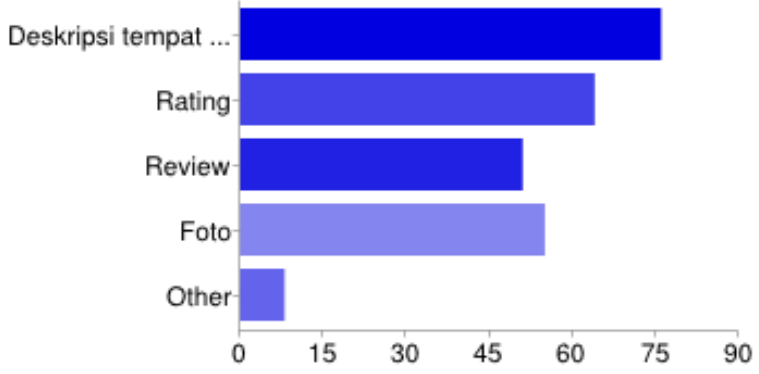

Gambar 6 Kebutuhan Fitur

Pertanyaan terakhir tentang radius pencarian tempat wisata, sebanyak 61\% responden menginginkan radius pencarian lokasi wisata dari posisinya sejauh 26-50 kilometer. Data ini akan dijadikan rujukan dalam pengembangan aplikasi.

\section{Radius pencarian tempat wisata maksimum dari posisi Anda yang Anda inginkan?}

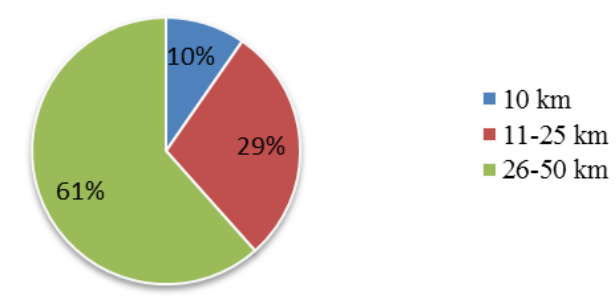

Gambar 7 Radius Pencarian Lokasi Wsata 


\section{Perancangan UML}

Perancangan sistem yang digunakan untuk merancang sistem pada aplikasi adalah perancangan UML yang meliputi Class Diagram dan Use Case Diagram. Use Case Diagram (Gambar 8) digunakan untuk menjabarkan tahap-tahap yang dilalui oleh aktor dalam melakukan setiap kegiatan yang berhubungan dengan sistem aplikasi (Sommerville, 2011). Pada Use Case Diagram berikut ini terdapat dua aktor, yaitu User dan Admin. Aktor User berfungsi sebagai pengguna yang dapat mencari dan menampilkan lokasi wisata, mendapatkan rute, dan melakukan rating. Adapun aktor Admin melakukan pengelolaan terhadap lokasi wisata.

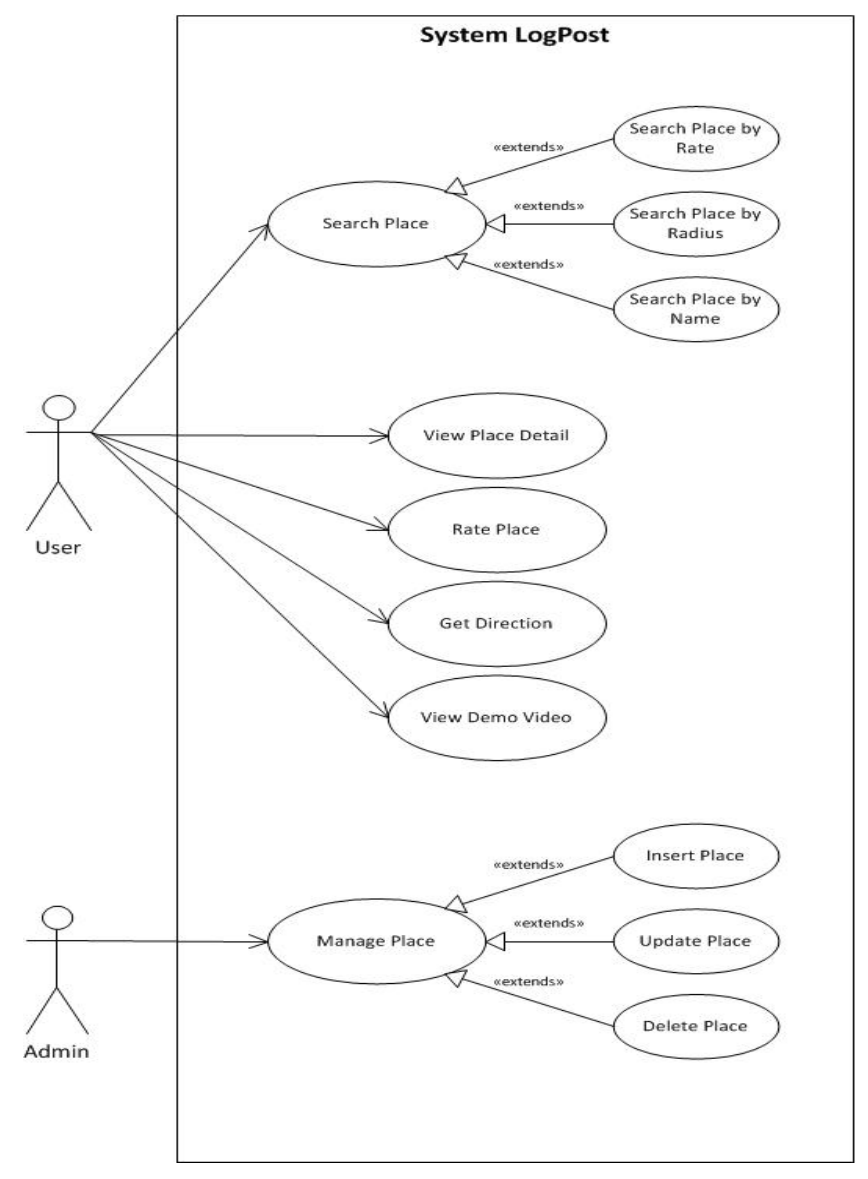

Gambar 8 Use Case Diagram

Class Diagram (Gambar 9) digunakan untuk menggambarkan struktur pemodelan dari sistem aplikasi yang dibangun (Sommerville, 2011). Setiap class mewakili setiap entity pada sistem dan terdiri dari properti serta perilaku dari class tersebut. Sebagai contoh, Class Place memiliki beberapa atribut seperti Image, Name, Address, Longitude, dan TotalRate yang merupakan detil data lokasi wisata (gambar, nama, alamat, koordinat, dan rating), dan perilaku UpdatePlaceRate agar dapat memperbarui rating lokasi tersebut. Class Route memiliki beberapa atribut seperti userLongitude, dan destinationLongitude yang berfungsi untuk menyimpan koordinat pengguna dan lokasi wisata, dan perilaku GetDestinationLocation dan DrawRoute untuk menampikan lokasi wisata berdasarkan perhitungan radius dari titik koordinat pengguna ke lokasi wisata dan menggambarkan rute perjalanan menuju lokasi wisata tersebut. 


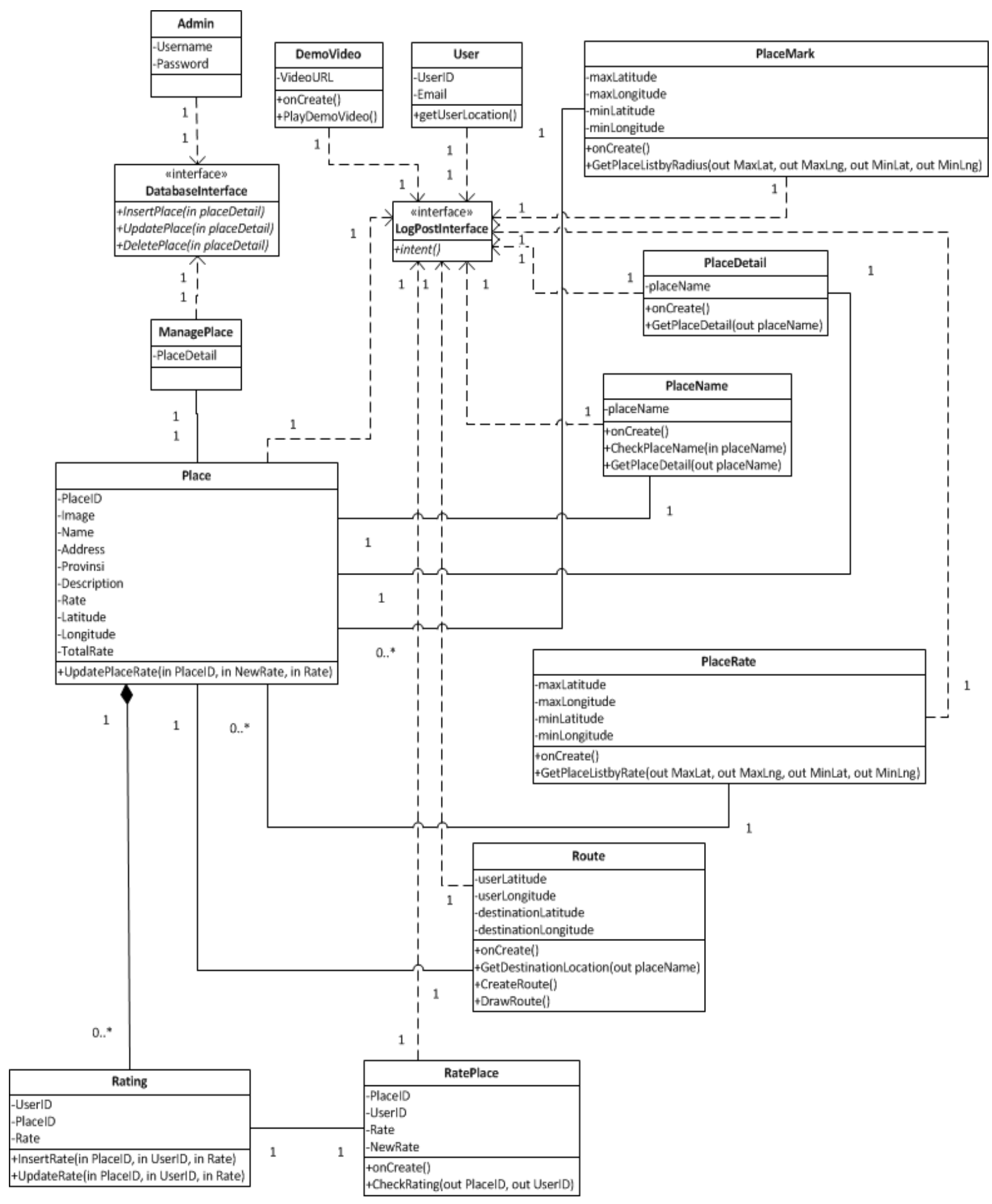

Gambar 9 Class Diagram

\section{Perancangan Basis Data}

Basis data digunakan untuk menyimpan data yang diperlukan pada sistem aplikasi (Connolly Begg, 2005). Terdapat 3 tabel utama yang digunakan pada sistem aplikasi sebagai berikut. 


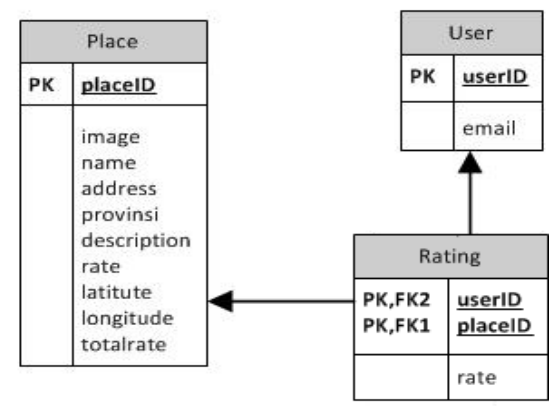

Gambar 10 Diagram Basis Data

Setiap tabel mewakili entitas data pada sistem. Sebagai contoh, tabel User digunakan untuk menyimpan data yang berkaitan dengan pengguna, tabel Place digunakan untuk menyimpan data yang berkaitan dengan lokasi wisata, dan tabel Rating digunakan untuk menyimpan data yang berkaitan dengan pemeringkat lokasi wisata.

\section{Pengembangan dan Implementasi Peranti Lunak}

Aplikasi dikembangkan pada spesifikasi perangkat keras yaitu memory sebesar 64MB (minimum) dan 128MB (rekomendasi), storage sebesar 2MB (minimum) dan 5 MB (rekomendasi), dan memiliki fitur GPS. Pada tahap pengujian, aplikasi diujicobakan pada 3 perangkat sebagai berikut dan dapat berjalan dengan baik.

Tabel 1 Spesifikasi Perangkat untuk Pengujian Aplikasi

\begin{tabular}{lccc}
\hline Perangkat Keras & Sony Ericson Xperia X8 & Samsung Galaxy S II & Samsung Galaxy S III \\
\hline Memory & $168 \mathrm{MB}$ & $1 \mathrm{~GB}$ & $1 \mathrm{~GB}$ \\
Storage & $128 \mathrm{MB}$ & $16 \mathrm{~GB}$ & $32 \mathrm{~GB}$ \\
GPS & Ya & Ya & Ya \\
Operating System & Android OS, v2.3 Gingerbread & Android OS, v4.0.4 Ice & Android OS, v4.1 \\
& & Cream Sandwich & JellyBean \\
Internet & 3G, HSDPA & 3G, HSDPA & 3G, HSDPA \\
\hline
\end{tabular}

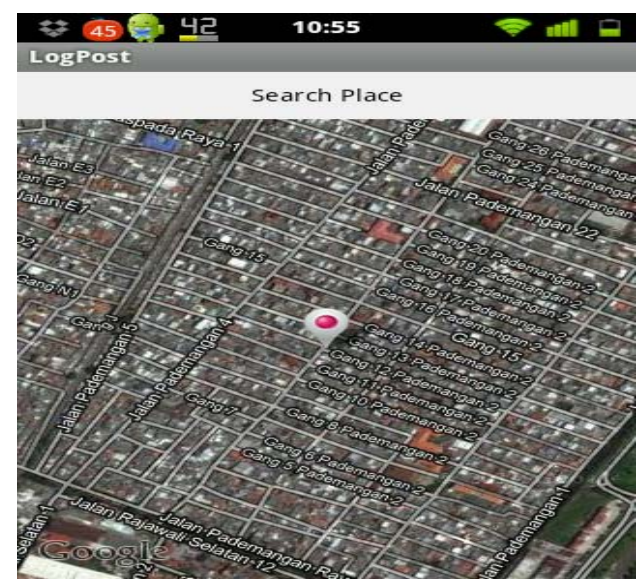

Gambar 11 Tampilan Halaman Utama 
Pada halaman menu utama, wisatawan akan melihat tanda posisi wisatawan dan menu "Search Place” untuk melakukan pencarian tempat. Wisatawan dapat melakukan pembesaran atau pengecilan gambar peta.
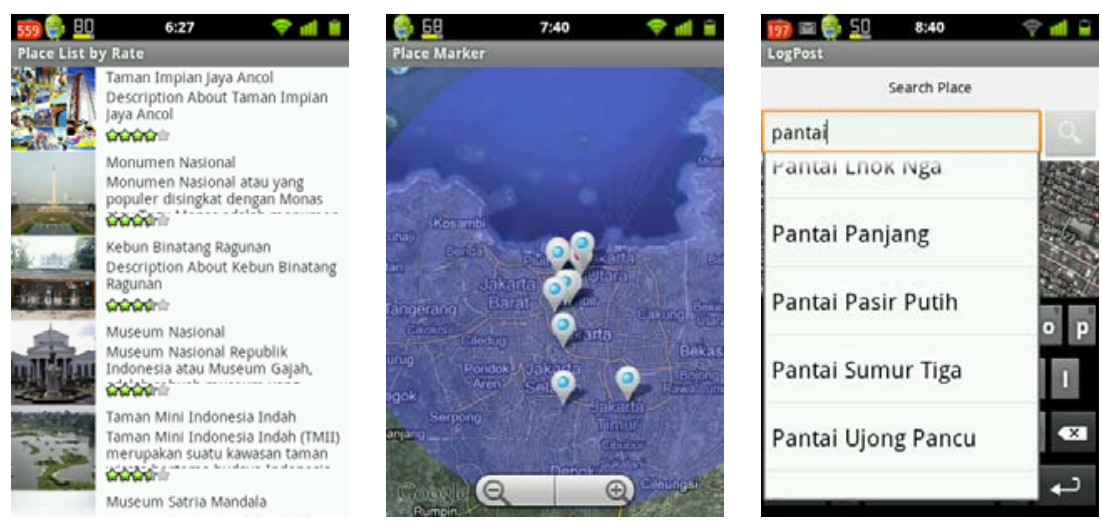

Gambar 12 Tampilan Search By (a) Rate, (b) Radius, dan (c) Name

Pada halaman "Search by Rate", pencarian tempat wisata dilakukan berdasarkan rating. Halaman ini menyajikan gambar dan deskripsi tempat wisata. Pada halaman "Search by Radius", pencarian tempat wisata dilakukan dengan radius $50 \mathrm{~km}$ dari posisi wisatawan. Pada halaman "Search by Name”, pencarian tempat wisata dilakukan berdasarkan pencarian nama (auto-complete).
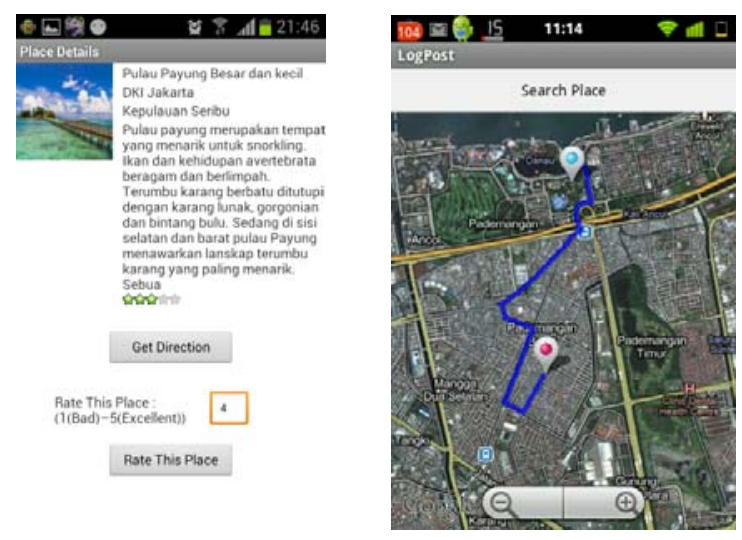

Gambar 13 Tampilan Halaman (a) Place Details dan (b) Route

Pada halaman ini, wisatawan akan mendapatkan deskripsi tempat wisata yang dilengkapi foto, nama tempat, dan rating. Wisatawan dapat mencari rute jalan dari posisi wisatawan ke tempat wisata tersebut dan melakukan rating.

\section{Evaluasi}

Evaluasi terhadap aplikasi dilakukan pada faktor 8 aturan emas Interaksi Manusia dan Komputer (Shneiderman \& Plaisant, 2010), 5 elemen multimedia, dan kuesioner yang ditujukan pada pengguna. Pengkajian terhadap 8 aturan emas mencakup (1) konsistensi penggunaan icon untuk navigasi, peletakan menu, penggunaan warna untuk menu, teks dan font, (2) penggunaan shortcut sehingga memungkinkan pengunjung menggunakan keys tertentu untuk mengakses suatu area, (3) 
ketersediaan respon atau umpan balik yang informatif ketika tombol ditekan, (4) ketersediaan dialog sederhana yang menampilkan keadaan akhir suatu proses, (5) pesan kesalahan kepada pengguna ketika terjadi kesalahan input, (6) ketersediaan tombol back agar pengguna dapat kembali melihat menu sebelumnya, (7) pusat kendali internal berupa respons yang sesuai dengan aksi yang diinginkan pengguna, dan (8) perancangan dengan konsep sederhana agar pengguna tidak perlu melakukan penghapalan yang terlalu banyak atas fitur-fitur yang tersedia.

Evaluasi 5 elemen multimedia (Vaughan, 2011) mencakup (1) teks yang digunakan, (2) gambar lokasi wisata dan peta, (3) animasi rute, (4) komponen suara, dan (5) video yang dapat dilihat oleh pengguna.

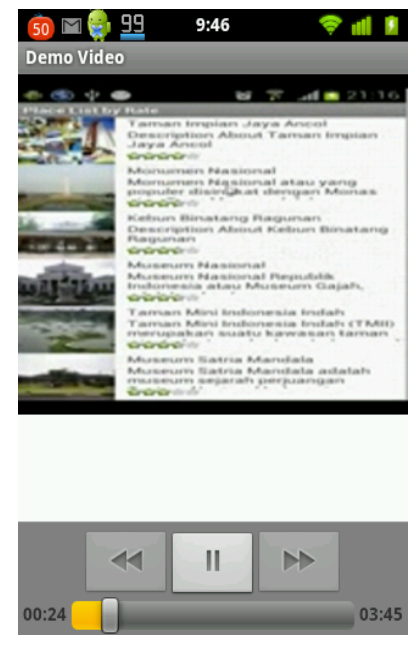

Gambar 14 Tampilan 5 Elemen Multimedia

Evaluasi terhadap aplikasi hasil penelitian juga dilakukan melalui kuesioner yang diberikan pada 41 responden. Hasil dari kuesioner evaluasi tersebut ditampilkan pada grafik berikut.

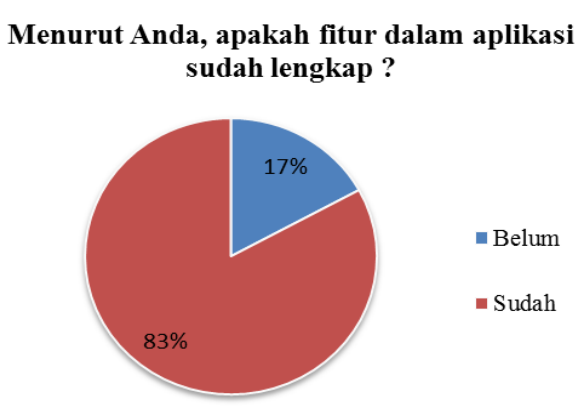

Gambar 15 Evaluasi Kelengkapan Fitur

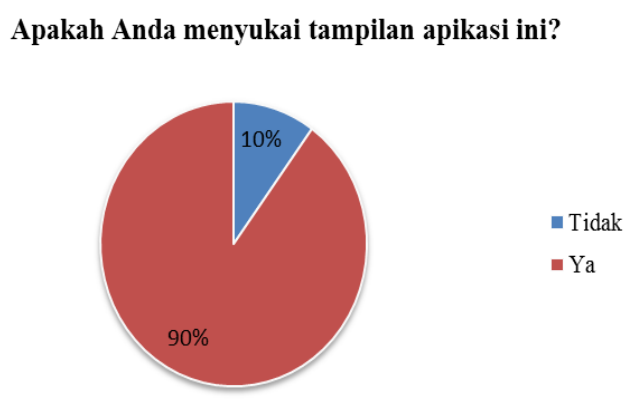

Gambar 16 Evaluasi Ketertarikan Tampilan 
Menurut Anda, apakah aplikasi ini mudah

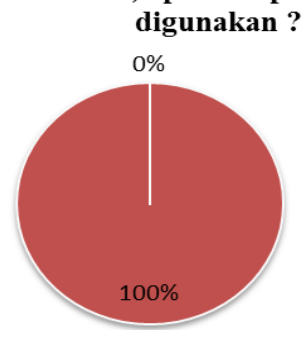

Gambar 17 Evaluasi Kemudahan Penggunaan
Dalam penggunaanya apakah aplikasi ini membantu Anda dalam menemukan tempat wisata?

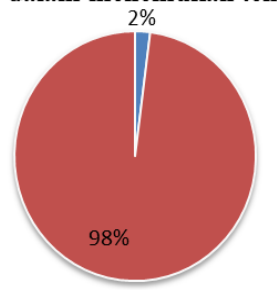

Gambar 18 Evaluasi Dukungan Aplikasi

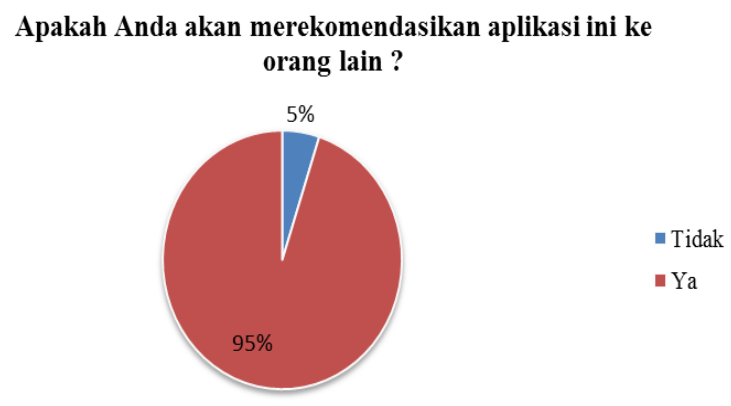

Gambar 19 Evaluasi Rekomendasi

\section{SIMPULAN}

Simpulan yang diperoleh dari penelitian ini adalah aplikasi memberi kemudahan kepada wisatawan dalam mencari tempat wisata berdasarkan rating, nama, dan radius; membantu dalam memberikan penunjuk jalan tempat wisata; dan memberi kemudahan kepada wisatawan untuk mengetahui informasi berupa deskripsi tempat wisata, foto, dan rating.

Saran untuk penelitian dan pengembangan lebih lanjut yaitu melengkapi aplikasi dengan daftar hotel, restoran, dan rumah sakit agar menunjang wisatawan dalam berwisata (Shoval, McKercher, Ng, et al, 2011), menyediakan fitur perbesaran foto pada lokasi wisata, transportasi yang dapat diakses (Edwards \& Griffin, 2013), dan menyediakan fitur bagi wisatawan untuk menulis review suatu lokasi wisata.

\section{DAFTAR PUSTAKA}

Chu, T. H., Lin, M. L., Chang, C. H., \& Chen, C. W. (2011). Developing a tour guiding information system for tourism service using mobile GIS and GPS techniques. Advances in Information Sciences and Service Sciences, 3(6), 49-58.

Connolly, T., \& Begg, C. (2005). Database Systems A Practical Approach to Design, Implementation, and Management (4th ed). New York: Addison-Wesley.

Edwards, D., \& Griffin, T. (2013). Understanding tourists’ spatial behaviour: GPS tracking as an aid to sustainable destination management. Journal of Sustainable Tourism, 21(4). DOI:10.1080/09669582.2013.776063 
Feng, Y., Rizos, C., Higgins, M., Lim, S., \& Tang, M. (2009). Developing regional precise positioning services using the legacy and future GNSS receivers. Journal of Global Positioning Systems, $8(1), 17-25$.

Hallo, J. C., Beeco, J. A., Goetcheus, C., McGee, J., McGehee, N. G., \& Norman, W. C. (2012). GPS as a Method for Assessing Spatial and Temporal Use Distributions of Nature-Based Tourists. Journal of Travel Research, 51(5), 591-606.

Ismayanti. (2011). Pengantar Pariwisata. Jakarta: Grasindo.

Kementerian Pariwisata dan Ekonomi Kreatif Indonesia. (2012). Ranking Devisa 2006 - 2010. Diakses dari http://www.budpar.go.id/budpar/asp/ringkasan.asp?c=117

Khraisat, Y. S., Al-Khateeb, M., Abu-Alreesh, Y., Ayyash, A., \& Lahlouh, O. (2011). GPS navigation and tracking device. International Journal of Interactive Mobile Technologies, 5(4), 39-41.

Lai, P.C., Li, C. L., Chan, K. W., \& Kwong, K. H. (2007). An Assessment of GPS and GIS in Recreational Tracking. Journal of Park and Recreation Administration, 25(1), 128-139.

Ruotsalainen, L., Kuusniemi, H., \& Chen. R. (2011). Visual-aided two-dimensional pedestrian indoor navigation with a smartphone. Journal of Global Positioning Systems, 10(1), 11-18.

Shneiderman, B., \& Plaisant, C. (2010). Designing The User Interface (5th ed). Boston: AddisonWesley.

Shimizu, T., Yamaguchi, T., Ai, H., Kawase, J., \& Katagiri. Y. (2014). Travel path and transport mode identification method using "Less-Frequently-Detected" position data. 8th International Symposium of the Digital Earth (pp. 1-6).

Shoval, N., McKercher, B., Ng, E., Birenboim. A. (2011). Hotel location and tourist activity in cities. Annals of Tourism Research, 38(4), 1594-1612.

Simon, D. P., \& Williams. (2008). CATS: GPS coordinate time series analysis software. GPS Solutions, 12(2), 147-153.

Sommerville, I (2011). Software Engineering (9th ed). Boston: Addison-Wesley.

Steiniger, S., Neun, M., \& Edwardes, A. (2006). Foundations of Location Based Services. CartouCHe1-Lecture Notes on LBS, 1, 2.

Vaughan, T. (2011). Multimedia: Making It Work (8th ed). New York: McGraw-Hill.

Whitten, J. L., \& Bentley, L. D. (2007). System Analysis and Design Methods (7th ed). New York: McGraw-Hill.

Yulianto, B. (2010). Teknologi location based service (Global Positioning System) pada perangkat mobile. Jurnal ComTech, 1(1), 61-74. 